\title{
FORMULATION AND EVALUATION OF TOPICAL HERBAL GEL CONTAINING INCLUSION COMPLEX OF CURCUMIN
}

\author{
VANDANA D*, SHWETA PAWAR
}

Department of Pharmaceutics, Gokaraju Rangaraju College of Pharmacy, Hyderabad, Telangana, India. Email: vandana18d@gmail.com Received: 11 May 2019, Revised and Accepted: 22 July 2019

\begin{abstract}
Objective: The current work was aimed to prepare a topical gel containing curcumin (CUR) for the treatment of microbial infections on skin.

Methods: CUR was complexed with the $\beta$-cyclodextrin ( $\beta$-CD) using kneading method in 1:1, 1:2, and 1:3 molar ratios and characterized. The inclusion complex with high aqueous solubility was loaded in the topical gel containing (2\% CUR) which was prepared using carbopol, sodium $\mathrm{CMC}$, and guar gum and evaluated for viscosity, spreadability, extrudability, $\mathrm{pH}$, drug content, and in vitro diffusion studies. The in vitro antiinflammatory activity of the gel was performed by albumin protein denaturation technique, the statistical analysis was done using ANOVA followed Dunnett's t-test. The antimicrobial activity of CUR was evaluated using standard strains of Candida albicans and Escherichia coli by agar well diffusion method.
\end{abstract}

Results: The complexation of CUR had an increased solubility up to 103.09 times for 1:3 molar ratio with in vitro dissolution $90.64 \%$ for 60 min. The optimized formulation F9 had viscosity of $6500.3 \mathrm{cps}$ and $97.5 \%$ in vitro drug diffusion for $8 \mathrm{~h}$ which follows zero-order release kinetics. In vitro antiinflammatory activity studied showed that the CUR gel has a good potency for renaturation and was as effective as standard diclofenac with $76.9 \%$ inhibition ( $\mathrm{p}=0.0507)$. CUR showed approx. $3 \mathrm{~mm}$ diameter of zone of inhibition against C. albicans and E. coli.

Conclusion: A stable topical gel of CUR using $\beta$-CD and carbopol was successfully prepared which showed better in vitro diffusion with promising anti-inflammatory and antifungal action.

Keywords: Curcumin, $\beta$-Cyclodextrin, Inclusion complex, Antimicrobial activity, Albumin protein denaturation, Anti-inflammation, ANOVA.

(C) 2019 The Authors. Published by Innovare Academic Sciences Pvt Ltd. This is an open access article under the CC BY license (http://creativecommons. org/licenses/by/4. 0/) DOI: http://dx.doi.org/10.22159/ajpcr.2019.v12i9.34053

\section{INTRODUCTION}

Herbal medicines are still the mainstay of about 75-80\% of the world's population, majorly in developing countries due to better cultural acceptability, better compatibility with the human body, complete cure, and lesser side effects. It is estimated that approximately one-quarter of prescribed drugs contain plant extracts or active ingredients obtained from or modeled on plant substances [1].

Water insolubility, low potency, and instability are inherent problems of several herbal medicines. Curcumin (CUR) is a polyphenolic phytochemical constituent of Curcuma longa (Family - Zingiberaceae) chemically known as diferuloylmethane. CUR [1,7-Bis-(4-hydroxy-3methoxyphenyl)-hepta-1,6-diene-3,5-dione] is an oil-soluble pigment, practically insoluble in water at acidic and neutral $\mathrm{pH}$, soluble in alkali, and highly susceptible for $\mathrm{pH}$ change having molecular weight $368.38 \mathrm{~g} / \mathrm{mole}$ and a melting point of $175-180^{\circ} \mathrm{C}$ [2]. Following oral administration (up to $8 \mathrm{~g} /$ day), it is poorly absorbed and only the traces of compound appear in blood. It undergoes extensive first-pass metabolism and hence is a suitable candidate for topical gel formulation $[2,3]$.

It has been used from the time immemorial as a dietary supplement, coloring agent and spice, and for curing the diseases. It has been reported to possess anti-inflammatory, antibacterial, antifungal, anticancer, antispasmodic, antioxidant, anti-amebic, anti-HIV, and antidiabetic activity [4-6].

Although it has shown many excellent pharmacological activities, it has not yet been approved for use as a drug due to the very low bioavailability obtained after oral administration, which is due, in part, to poor solubility $11 \mathrm{ng} / \mathrm{mL}$ in aqueous buffer, $\mathrm{pH} 5.5$, and stability $\left(\mathrm{t}_{1 / 2}\right.$ of CUR in PBS pH $\left.7.2<10 \mathrm{~min}\right)$ [4].
CUR has also been shown to counter inflammatory responses similarly to the action of steroids, but without side effects. Considering the fact that, most inflammatory diseases occur locally and near the surface of the body, topical application of CUR on the inflamed site can offer the advantage of delivering a drug directly to the disease site and producing its local effect. Inflammation is a complex process, which is frequently associated with pain and involves occurrences such as the increase of vascular permeability and increase of protein denaturation and membrane alteration [4]. CUR exhibits its antiinflammatory effect by increasing cortisone production by adrenal glands and by inhibiting prostaglandin also by decreasing histamine levels.

There have been concerns related to the conventional topical dosage forms such as lotions, creams, ointments, and powder in terms of drug diffusion or release from the vehicle and delivery through the skin. The current work was aimed to prepare a topical gel containing CUR for the treatment of microbial infections on skin.

\section{MATERIALS AND METHODS}

\section{Materials}

CUR was purchased from Sisco Research Laboratories (SRL, Mumbai, India), CAS Number: [458-37-7]. $\beta$-Cyclodextrin ( $\beta$-CD), carbopol, sodium CMC, guar gum, and menthol were obtained from SD FineChem Limited, Chennai, India. Dimethyl sulfoxide (DMSO) and triethanolamine were received from Loba Chemie Pvt. Ltd., Mumbai, India. All other chemicals used in the study were of analytical grade. Standard strain of Escherichia coli (ATCC ${ }^{\circledR} 12435$ ) and Candida albicans (ATCC $\left.{ }^{\circledR} 18804\right)$ was purchased from HiMedia Laboratories Pvt. Ltd., Ghatkopar (West), Mumbai, Maharashtra, India. 


\section{Methods}

\section{Pre-formulation studies}

Determination of melting point

Melting point was determined by capillary fusion method. One-sided sealed capillary tube was taken and filled with the CUR in sufficient amount and kept inside the melting point apparatus. The temperature at which CUR gets molten was noted and the readings were taken in triplicate and compared with literature value.

Partition coefficient

About $10 \mathrm{mg}$ of CUR was added to $50 \mathrm{ml}$ of octanol in a stopper bottle and kept in the orbital shaker at $37^{\circ} \mathrm{C}$ for $24 \mathrm{~h}$. About $50 \mathrm{ml}$ of distilled water was then added to the bottle with shaking at same temperature for another $24 \mathrm{~h}$. Two layers were then separated using a separating funnel, the absorbance of the CUR in the aqueous layer was determined at $427 \mathrm{~nm}$ and the concentration was determined by calibration curve. The concentration of CUR in octanol was determined by difference.

$$
\text { Partition coefficient }=\frac{\text { Concentration of CUR in organic phase }}{\text { Concentration of CUR in aqueous phase }}
$$

\section{Drug-excipient compatibility studies}

UV spectroscopy

CUR, CUR and excipients mixtures, and excipient mixtures were diluted with pH 6.8 phosphate buffer and scanned the solutions of above using UV spectrophotometer. The characteristic peaks of CUR, CUR and excipients mixtures, and excipients mixtures were compared at $\lambda_{\max }$ of $427 \mathrm{~nm}[7]$.

\section{Fourier transform infrared (FTIR)}

The CUR excipient compatibility studies were conducted by comparing the IR spectrum of CUR and different excipients mixtures and identifying the characteristic peaks of CUR. The IR spectrum of CUR and its mixtures were obtained using potassium bromide disc technique. The observed characteristic absorption peaks of CUR were compared with literature data [8].

\section{Formulation development}

Preparation of inclusion complex (IC) by kneading method

CUR and $\beta$-CD in the molar ratio of $1: 1,1: 2$, and 1:3 were taken and added in the mortar and kneaded for $45 \mathrm{~min}$. During kneading, methanol: water $(25: 75 \mathrm{v} / \mathrm{v})$ mixture was added and triturated until dense paste was formed. The product was dried in oven at $40^{\circ} \mathrm{C}$ for $24 \mathrm{~h}$ until constant weight was obtained and was passed through sieve no 80 .

\section{Characterization of IC}

DSC studies

The IC was characterized to confirm that the IC had formed using differential scanning calorimetry. The IC was studied in comparison with CUR. For DSC, the samples ( $3 \mathrm{mg}$ ) were heated from $50^{\circ} \mathrm{C}$ to $200^{\circ} \mathrm{C}$ using a temperature rate of $10^{\circ} \mathrm{C} / \mathrm{min}$. A nitrogen purge of $100 \mathrm{~mL} / \mathrm{min}$ was used [9].

\section{Percentage yield}

The percentage yield of the IC was calculated based on the dry weight of CUR and $\beta$-CD initially added (theoretical yield), and the final weight of the molar IC after kneading (practical yield).

Percentage yield $=\frac{\text { Practical } \text { yield }}{\text { Theoretical } \text { yield }} \times 100$

\section{Drug content}

The amount of CUR present in the $\beta$-CD complex was estimated by UV spectrophotometric method. About $10 \mathrm{mg}$ of the IC was accurately weighed and dissolved in methanol, the solution was suitably diluted, and the absorbance was measured at $427 \mathrm{~nm}$ and the CUR content was calculated using the regression equation.

\section{Solubility studies}

The solubility of inclusion complexes was studied in comparison with CUR in distilled water. About $10 \mathrm{mg}$ of CUR, $10 \mathrm{mg}$ of equivalent weight of CUR containing IC of $1: 1,1: 2$, and $1: 3$ were weighed accurately and added to stoppered bottle containing water until it reached its saturation point. The bottles were shaken continuously for $24 \mathrm{~h}$ at $37^{\circ} \mathrm{C}$ and $75 \mathrm{rpm}$ in an orbital shaker. After $24 \mathrm{~h}$, the solutions were filtered and further dilutions were made. The absorbance was measured at $427 \mathrm{~nm}$ and the solubility was determined by regression equation.

\section{In vitro dissolution studies of IC}

To evaluate the CUR and IC release profiles, dissolution studies using Type-II dissolution apparatus were performed. Inclusion complexes equivalent to $10 \mathrm{mg}$ of CUR were placed in the dissolution vessel containing $900 \mathrm{ml}$ of $\mathrm{pH} 6.8$ phosphate buffers, maintained at $37^{\circ} \mathrm{C}$, and stirred at $75 \mathrm{rpm}$. About $5 \mathrm{ml}$ of aliquots were withdrawn at fixed intervals of $10,20,30,40,50$, and $60 \mathrm{~min}$ and equal volume of fresh medium was replaced. Samples were filtered and absorbance was read at $427 \mathrm{~nm}$ against blank.

\section{Preparation of gel using simple dispersion method}

Accurately weighed polymer was taken in beaker and dispersed in $50 \mathrm{ml}$ of water and kept aside for $30 \mathrm{~min}$, it was stirred at $1200 \mathrm{rpm}$ for 30 min under mechanical stirrer. To it required quantity of CUR+ $\beta-C D$, which is dissolved in water, is added. DMSO, menthol, and parabens which were dissolved in methanol were added to the above preparation and final volume was adjusted with the water and $\mathrm{pH}$ was adjusted with triethylamine [9]. The amount of polymers used in the gel was according to their recommended concentration [10].

\section{Evaluation parameters for gel \\ Physical parameters}

Physical parameters such as color and appearance were checked visually.

\section{Measurement of $\mathrm{pH}$}

About $1 \mathrm{~g}$ gel was accurately weighed and dispersed in $100 \mathrm{ml}$ purified water. The $\mathrm{pH}$ of the dispersion was measured using digital $\mathrm{pH}$ meter.

The measurements of $\mathrm{pH}$ were done in triplicate and average values were calculated.

\section{Drug content}

About $1 \mathrm{~g}$ of gel was weighed and dissolved in $100 \mathrm{ml}$ of 6.8 phosphate buffer; appropriate dilutions were made with buffer and filtered. The absorbance of the solution was measured spectrophotometrically at $427 \mathrm{~nm}$ [11].

\section{Spreadability}

About $0.5 \mathrm{~g}$ of gel was placed in a circle of $1 \mathrm{~cm}$ diameter on a $20 \times 20 \mathrm{~cm}$ glass plate, over which the second glass plate is placed. Weight of $500 \mathrm{~g}$ was allowed to rest on upper glass plate for $5 \mathrm{~min}$ and then increase in diameter of the gel due to spreading was noted [11].

\section{Extrudability}

A closed collapsible tube containing formulation was pressed firmly at the crimped end. When the cap was removed, formulation extruded until the pressure dissipated. Weight in mg required to extrude a $0.5 \mathrm{~cm}$ ribbon of the formulation in $10 \mathrm{~s}$ was determined.

\section{Viscosity}

The measurement of viscosity of the prepared gel was done with a DV-E Brookfield viscometer. The gels were rotated at $30 \mathrm{rpm}$ using spindle no. 64 and the corresponding dial reading was noted. 


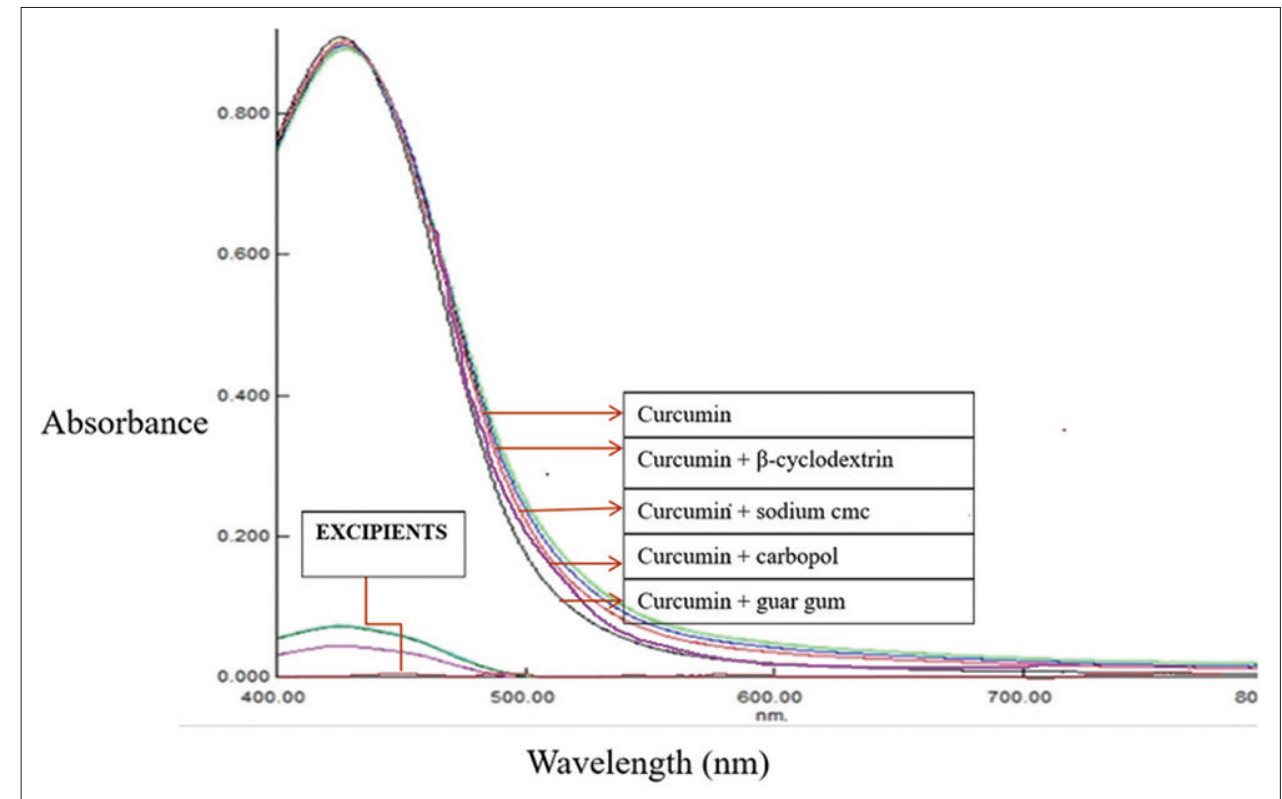

Fig. 1: An overlay spectrum of curcumin (CUR), CUR and excipient mixtures, and excipients of each in phosphate buffer pH - 6.8

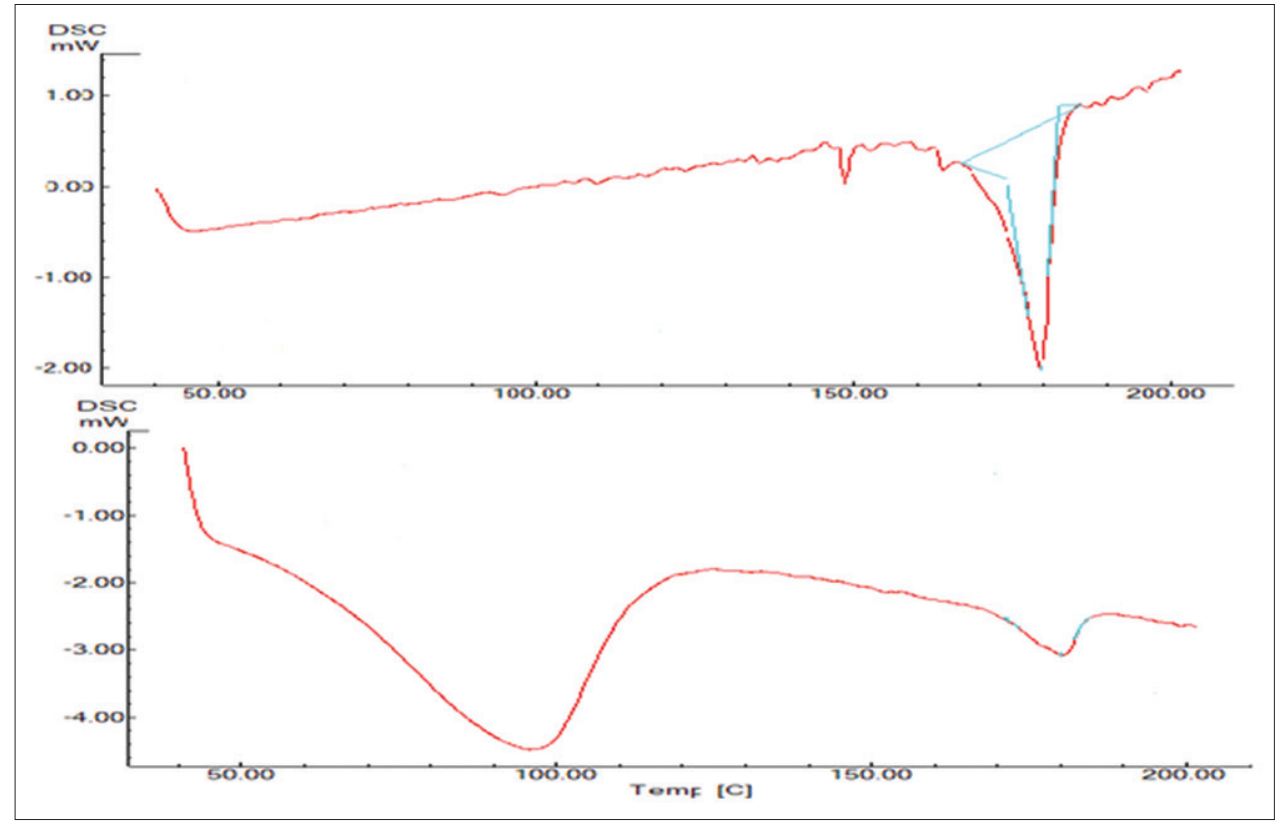

Fig. 2: Thermograms of curcumin and inclusion complex prepared by kneading method

\section{In vitro diffusion studies}

The in vitro release experiments were carried out using Franz-diffusion cells apparatus. About $1.0 \mathrm{~g}$ of gel was spread out on cellophane membrane positioned between the donor and receptor chamber. The receptor compartment was filled with phosphate buffer $\mathrm{pH} 6.8$ and continuously stirred with a small magnetic bar at a speed of $50 \mathrm{rpm}$ and maintained at $37 \pm 0.5^{\circ} \mathrm{C}$. The samples were withdrawn at various time intervals at 1, 2, 3, 4, 5, 6, 7, and $8 \mathrm{~h}$ and replaced with the same volume of buffer. The samples were analyzed spectrophotometrically at $427 \mathrm{~nm}$.

In vitro anti-inflammatory studies using albumin protein denaturation technique

The reaction mixture $(5 \mathrm{ml})$ consisted of $0.2 \mathrm{ml}$ of egg albumin (from fresh hen's egg) $2.8 \mathrm{ml}$ of PBS pH 6.4 and $2 \mathrm{ml}$ of gel solution so that final concentrations become 125, 250, 500, and $1000 \mu \mathrm{g} / \mathrm{mL}$. Diclofenac sodium was used as the standard drug and similar volume of double distilled water served as the control. The mixture was incubated at $37 \pm 2^{\circ} \mathrm{C}$ in a BOD incubator for $15 \mathrm{~min}$ and then heated at $70^{\circ} \mathrm{C}$ for $5 \mathrm{~min}$. After cooling, their absorbance was measured at $660 \mathrm{~nm}$ [12]

The percentage inhibition of protein denaturation was calculated using the following formula:

$$
\% \text { Inhibition }=\frac{\mathrm{Vt}}{\mathrm{Vc}-1} \times 100
$$

Where, $\mathrm{Vt}=$ Absorbance of the test sample and $\mathrm{Vc}=$ Absorbance of control.

\section{Antimicrobial studies by agar diffusion method} Antifungal studies

Sabouraud dextrose agar was transferred in a $500 \mathrm{ml}$ of conical flask and $250 \mathrm{ml}$ of purified water was added and heated on water bath to 
dissolve completely. Media were sterilized at $121^{\circ} \mathrm{C}$ at $15 \mathrm{lb}$ pressure in autoclave for about $20 \mathrm{~min}$. The fungal strain (C.albicans) was dispersed in the medium and poured it into the Petri dish and allowed it to cool until it solidifies. Then, the cups were prepared in each Petri dish with the help of sterile steel bore of $6 \mathrm{~mm}$. Gel formulation (F9) and placebo gel were placed in the cup and incubated for $72 \mathrm{~h}$ at $33^{\circ} \mathrm{C}$ in incubators, and the zone of inhibition was observed [12].

\section{Antibacterial studies}

Nutrient agar was transferred in a $500 \mathrm{ml}$ of conical flask and $250 \mathrm{ml}$ of purified water added and heated on water bath to dissolve completely. It was further sterilized at $121^{\circ} \mathrm{C}$ at $15 \mathrm{lb}$ pressure in autoclave for about $20 \mathrm{~min}$. The bacterial strain (E. coli) was dispersed in the medium and poured it into the Petri dish and allowed it to cool until it solidifies. Then, the cups were prepared in each Petri dish with the help of sterile steel bore of $6 \mathrm{~mm}$. Gel formulation (F9) and placebo gel were placed in the cup and incubated for $24 \mathrm{~h}$ at $37^{\circ} \mathrm{C}$ in incubators, and the zone of inhibition was observed [12].

\section{RESULTS AND DISCUSSION}

\section{Determination of melting point}

Melting point of CUR was found to be $178^{\circ} \mathrm{C}(\mathrm{n}=3)$.

\section{Determination of partition coefficient}

Partition coefficient is an important parameter as it is a measure of drugs lipophilicity and an indication of its ability to cross the cell membrane. The partition coefficient of CUR was found to be 3.13 , indicating it as a lipophilic drug.

Drug-excipient compatibility studies in pH 6.8 phosphate buffer using UV spectroscopy

It was observed that there was no incompatibility found between the CUR and excipients mixture used, as the CUR peak appeared when combined with each excipient.

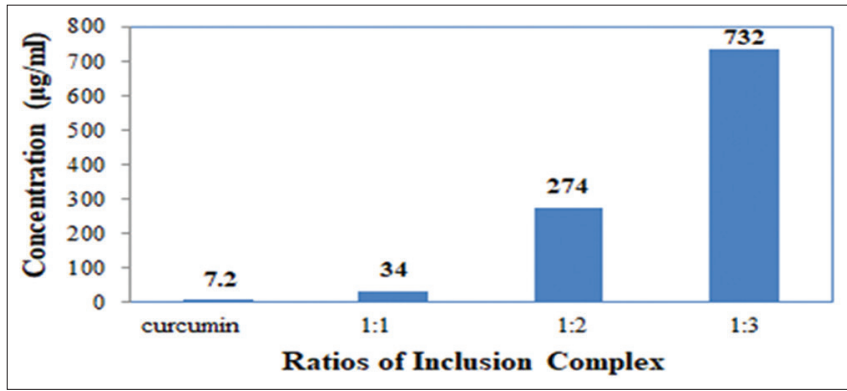

Fig. 3: Comparison of aqueous solubility profile of curcumin and inclusion complex

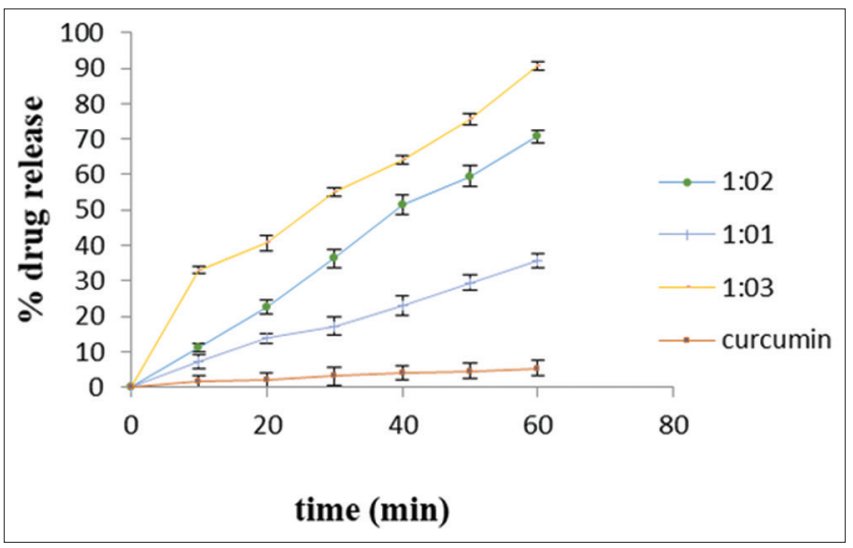

Fig. 4: In vitro dissolution profiles of curcumin and 1:1, 1:2, and 1:3 molar ratio inclusion complexes (mean $\pm S D, n=3$ )
FTIR studies

The FTIR spectra of CUR and with mixtures of excipients $(\beta-C D$, carbopol, sodium CMC, and guar gum) were determined. IT spectrum of the CUR matched with that of literature value. The characteristic peaks of CUR were shown in all the CUR and excipient mixtures, which indicated compatibility of the drug with the excipients used.

\section{Characterization of IC}

DSC studies

CUR showed the endothermic peak at $179^{\circ} \mathrm{C}$ consistency with its melting point. The thermogram of IC prepared by kneading method showed endothermic peak at $180^{\circ} \mathrm{C}$. The peak was enormously reduced compared to that of CUR, indicating the formation of IC.

The percentage yield, drug content, and solubility of the prepared inclusion complexes prepared by kneading method are given in Table 2 . The 1:1 ratio IC enhanced the aqueous solubility up to 4.78 times (34 $\mu \mathrm{g} / \mathrm{ml}), 1: 2$ ratio enhanced to 38.59 times $(274 \mu \mathrm{g} / \mathrm{ml})$, and for $1: 3$ ratio, it enhanced up to 103.09 times $(732 \mu \mathrm{g} / \mathrm{ml})$ compared to CUR. The drug release profiles for the prepared inclusion complexes in comparison with CUR for a period of $1 \mathrm{~h}$ at $10 \mathrm{~min}$ intervals were performed, at the end of $60 \mathrm{~min}$, percentage drug release for $1: 1$ is $35.7 \%, 1: 2$ is $70.6 \%$, and $1: 3$ is $90.64 \%$ when compared to CUR (5.4\%).

\section{Evaluation parameters of gel}

The prepared gel formulations were smooth, yellow in color, and homogenous in appearance. The $\mathrm{pH}$ values ranged from 6.8 to 6.9 for all the formulations which were in acceptable range to avoid skin irritation after application to the skin. All the gel formulations were found to contain $97.8-98.9 \%$ of CUR. Viscosity is an important physical parameter which will reflect the consistency in case of topical preparations and it also affects the rate of drug release. High viscosity

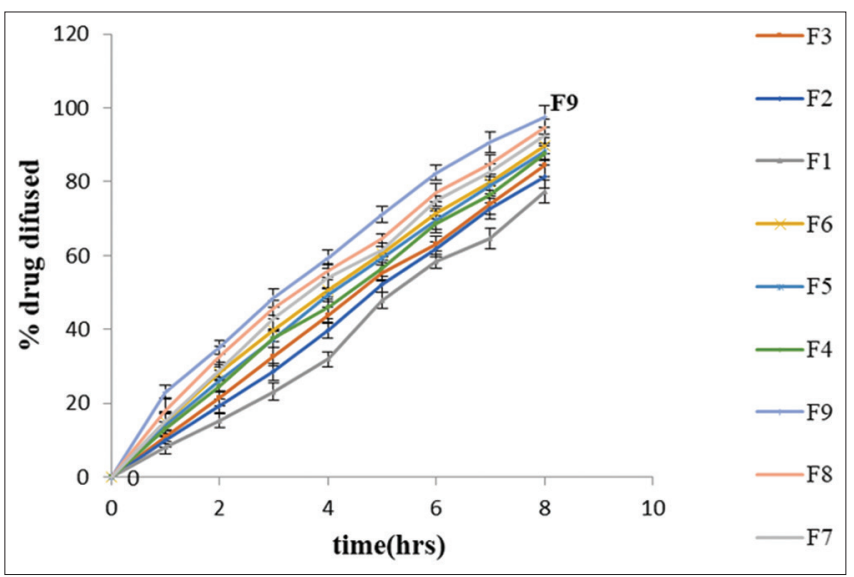

Fig. 5: In vitro drug diffusion profiles of various gel formulations F9 - Guar gum (1\%) diffused $97 \%$ drug at 8 h $($ mean $\pm S D, n=3)$

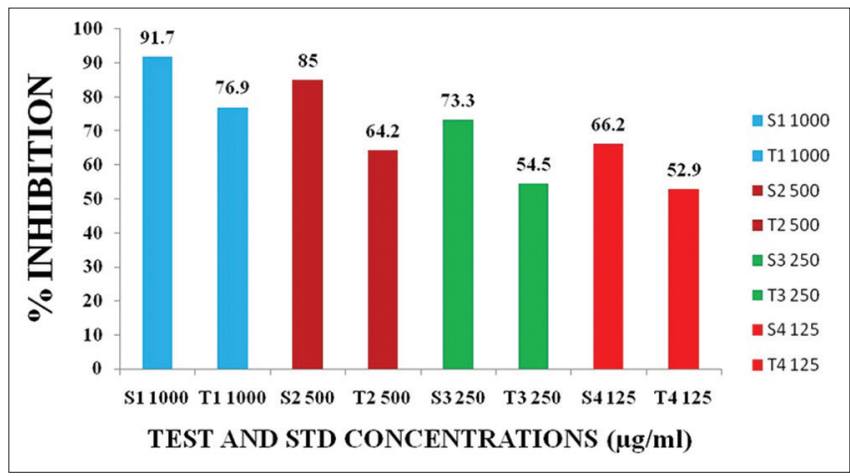

Fig. 6: Percentage inhibition of test and standard concentrations $($ Mean $\pm S D, n=3)$ 
Table 1: Formulation design of topical gel formulations*

\begin{tabular}{|c|c|c|c|c|c|c|c|c|c|}
\hline \multirow[t]{2}{*}{ Ingredients } & \multicolumn{9}{|l|}{$(\% \mathrm{w} / \mathrm{w})$} \\
\hline & F1 & F2 & F3 & F4 & F5 & F6 & F7 & F8 & F9 \\
\hline CUR inclusion complex & 2 & 2 & 2 & 2 & 2 & 2 & 2 & 2 & 2 \\
\hline Carbopol 934 & 2 & 1.5 & 1 & - & - & - & - & - & - \\
\hline $\mathrm{Na} \mathrm{CMC}$ & - & - & - & 5 & 4 & 3 & - & - & - \\
\hline Guar gum & - & - & - & - & - & - & 2 & 1.5 & 1 \\
\hline DMSO & 5 & 5 & 5 & 5 & 5 & 5 & 5 & 5 & 5 \\
\hline Menthol & 2 & 2 & 2 & 2 & 2 & 2 & 2 & 2 & 2 \\
\hline TEA & qs & qs & qs & qs & qs & qs & qs & qs & qs \\
\hline Methylparaben & 0.1 & 0.1 & 0.1 & 0.1 & 0.1 & 0.1 & 0.1 & 0.1 & 0.1 \\
\hline Propylparaben & 0.2 & 0.2 & 0.2 & 0.2 & 0.2 & 0.2 & 0.2 & 0.2 & 0.2 \\
\hline Methanol & 10 & 10 & 10 & 10 & 10 & 10 & 10 & 10 & 10 \\
\hline Water & Up to 100 & Up to 100 & Up to 100 & Up to 100 & Up to 100 & Up to 100 & Up to 100 & Up to 100 & Up to 100 \\
\hline
\end{tabular}

*Each batch was made at scale of 25 g. CUR: Curcumin, DMSO: Dimethyl sulfoxide

Table 2: Percentage yield, drug content, solubility of CUR, and $\beta$-cyclodextrin inclusion complexes*

\begin{tabular}{llll}
\hline CUR and $\beta$-cyclodextrin Inclusion complex (molar ratio) & Percentage yield (\%) & Drug content (\%) & Solubility (conc. $\boldsymbol{\mu g} / \mathbf{m l})$ \\
\hline $1: 1$ & $94.45 \pm 0.090$ & $97 \pm 0.05$ & 34 \\
$1: 2$ & $95.89 \pm 0.1$ & $95 \pm 0.2$ & 274 \\
$1: 3$ & $96.86 \pm 0.04$ & $94 \pm 0.09$ & 732 \\
CUR & - & - & 7.2 \\
\hline
\end{tabular}

*Data represented as Mean \pm SD, $n=3$. CUR: Curcumin

Table 3: Evaluation of gel parameters*

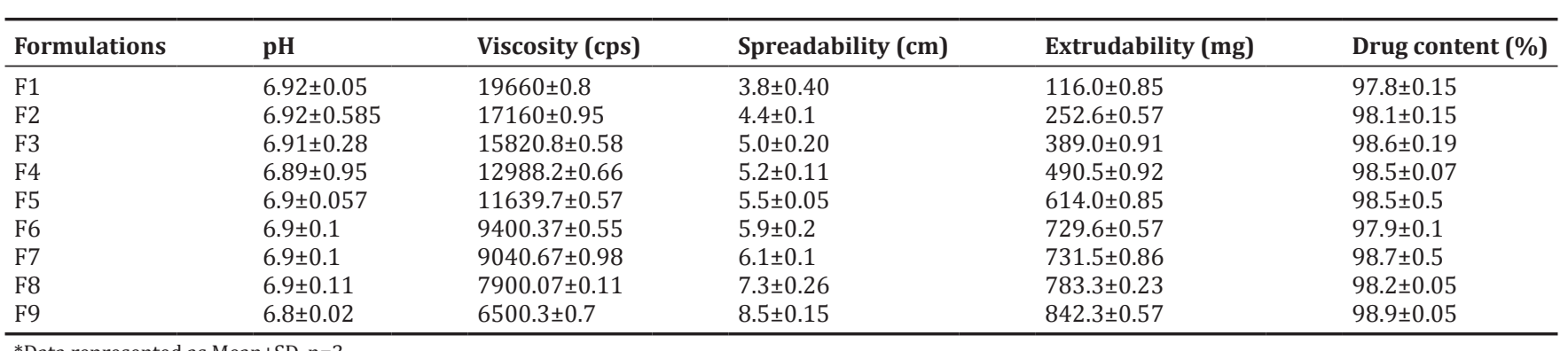

*Data represented as Mean \pm SD, $n=3$

is due to high polymeric entanglements; therefore, the resistance to deformation will be increased and it will lead to more rigid structure. The highest viscosity was found for F1 formulation due to high polymer concentration and F9 showed low viscosity.

F1formulation showed the lowest spreadability, due to the high polymer concentration. The ability of the gel to spread has decreased due to high polymeric entanglements, F9 shows high spreadability. The extrusion of the gel from the tube is an important parameter during its application and for its patient compliance. Gel with high consistency may not extrude from tube; hence, suitable consistency is required to extrude the gel from the tube. Extrudability of F1 formulation was found very less as it was highly viscous and extrudability of F9 formulation was satisfactory. The drug diffusion decreased for high polymer concentration due to high viscosity and increased for low polymer concentration due to low viscosity. Thus, both high viscosity and high concentration of polymer will compete in decreasing the drug release of active substance from formulation. High polymer concentration and decrease in drug release agree with Laufer molecular diffusion theory of gel, i.e. diffusion coefficient is inversely proportional to the volume occupied by polymer (gel-forming agent). High polymer concentration - increases viscosity - decreases spreadability - decreases drug diffusion, whereas low polymer concentration - decreases viscosity - increases spreadability - increases drug diffusion. F9 was selected as optimized formulation, it has viscosity of $6500 \mathrm{cps}$, greater in vitro drug diffusion of $97.5 \pm 0.5 \%$; further, anti-inflammatory and antimicrobial studies were performed.
Table 4: Mathematical model release kinetics of optimized batch

\begin{tabular}{llll}
\hline Model name & $\mathbf{r}^{2}$ & Slope & Intercept \\
\hline Zero order & 0.98 & 11.84 & 9.027 \\
First order & 0.87 & -0.176 & 2.160 \\
Higuchi model & 0.91 & 10.11 & 13.63 \\
Hixson-Crowell & 0.69 & -0.433 & 2.903 \\
Korsmeyer-Peppas & 0.38 & -0.518 & 2.264 \\
\hline
\end{tabular}

\section{Release kinetics}

The in vitro drug release data of the formulation F9 was fitted to various mathematical models, it showed linear nature between cumulative percentage drug released and time suggesting that it followed zeroorder kinetics. The best fit with higher correlation was found with zero order $\mathrm{r}^{2}=0.980$.

\section{In vitro anti-inflammatory study of gel}

CUR has shown dose-dependent ability to inhibit thermally-induced protein denaturation. Denaturation of proteins is a well-documented cause of inflammation [12]. The percentage inhibition for different concentrations of $1000,500,250$, and $125 \mu \mathrm{g} / \mathrm{ml}$ was calculated for test, standard, and control. The percentage inhibition of protein denaturation for test samples $\mathrm{T} 1, \mathrm{~T} 2, \mathrm{~T} 3$, and $\mathrm{T} 4$ was found to be $76.9 \%, 64.2 \%$, $54.5 \%$, and $52.9 \%$ and for standard samples S1, S2, S3, and S4 was found to be $91.7 \%, 85 \%, 73.3 \%$, and $66.2 \%$. As the concentration of test drug 
Table 5: \% Inhibition of test and standard concentrations $(n=3)$

\begin{tabular}{lllll}
\hline S. No. & Solution & $\begin{array}{l}\text { Concentration } \\
(\boldsymbol{\mu g} / \mathbf{m l})\end{array}$ & Absorbance & \% inhibition \\
\hline 1. & Control & - & $1.55 \pm 0.10$ & - \\
2. & Test 1 & 1000 & $0.34 \pm 0.003$ & 76.9 \\
3. & Test 2 & 500 & $0.54 \pm 0.003$ & 64.2 \\
4. & Test 3 & 250 & $0.69 \pm 0.0003$ & 54.5 \\
5. & Test 4 & 125 & $0.71 \pm 0.002$ & 52.9 \\
6. & Standard 1 & 1000 & $0.11 \pm 0.005$ & 91.7 \\
7. & Standard 2 & 500 & $0.21 \pm 0.006$ & 85 \\
8. & Standard 3 & 250 & $0.39 \pm 0.009$ & 73.3 \\
9. & Standard 4 & 125 & $0.51 \pm 0.004$ & 66.2 \\
\hline
\end{tabular}

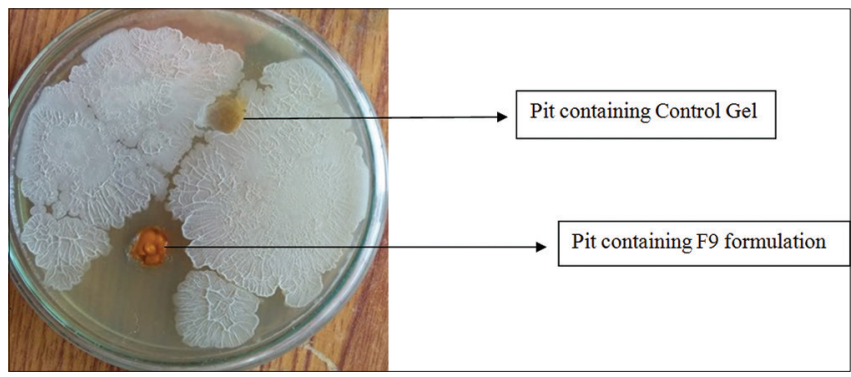

Fig. 7: Antibacterial zone of inhibition against strain Escherichia coli

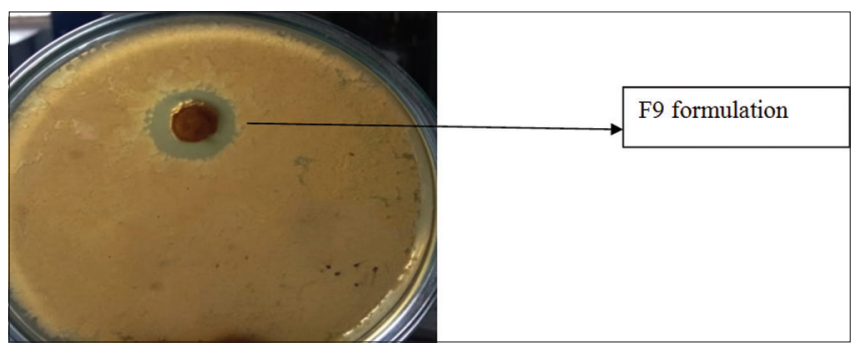

Fig. 8: Antifungal zone of inhibition against strain Candida albican

increased, a gradual increase in the protein renaturation was observed. Statistical analysis which was performed using ANOVA followed by Dunnett's t-test showed that there was a significant difference between test versus control and standard versus control. Significant values were expressed as $\mathrm{p}<0.0001^{* * * *}$ and there was no significant difference between test versus standard ( $p=0.0507)$. It indicated that the test has a good potency for renaturation, and it is as effective as that of standard. Therefore, the topical gel formulation of CUR developed in this study can have potential utility and these will be the viable option for effective and controllable management of inflammation [14].

\section{Antimicrobial studies}

In agar diffusion method, CUR diffuses through solidified agar medium and inhibits the growth of microbes near to the adjacent area of administration of CUR gel. As shown in Fig. 7, control sample showed no growth inhibition because antimicrobial agent was not added. Zone of growth inhibition (diameter $\approx 3 \mathrm{~mm}$ ) has been observed for $C$. albicans as shown in Fig. 8.

The results were comparable to the previous study [15], wherein a CUR tablets and placebo tablet were evaluated by cup-plate method.
Antifungal study with Sabouraud Culture shows that the CUR tablet was capable to control the growth of C. albicans for more than $24 \mathrm{~h}$.

\section{CONCLUSION}

From the study, it was concluded that IC of CUR had increased its aqueous solubility and stability. Gel formulation of CUR and $\beta$-cyclodextrin showed good potency for renaturation, indicating that CUR possesses anti-inflammatory activity. The studies revealed that CUR is exhibiting antifungal and antibacterial activity against the C. albicans and E. coli which enhance its potential for further clinical investigation.

\section{AUTHORS' CONTRIBUTIONS}

The first author carried out experiments. The second author made arrangement of drug and polymers and drafted the manuscript.

\section{CONFLICTS OF INTEREST}

The authors declared that there are no conflicts of interest.

\section{REFERENCES}

1. Ansari MJ, Ahmed MM, Fatima F, Anwer MK, Jamil S, Al-Shdefat R. Solubility and stability enhancement of curcumin through cyclodextrin complexation. Int J Biol Pharm Allied Sci 2014;3:2668-75.

2. Suresh D, Chaudhari YS, Borole P, Mishra PT, Shenghani K, Duvvuri P. Degradation studies of curcumin. Int J Pharm Res Rev 2013;3:50-5.

3. Shaveta S, Shweta P, Upendra J. Development and evaluation of topical gel of curcumin from different combination of polymers formulation and evaluation of herbal gel. Int $\mathrm{J}$ Pharm Pharm Sci 2012;4:452-6

4. Nikunjana A, Natvar J, Rakesh P. Formulation and evaluation of curcumin gel for topical application. Pharm Dev Technol 2009;14:83-92.

5. Nasreen S, Vijaya K. Prevention of peptic ulcers by curcumin in chemically induced osteoarthritis. Int J Pharm Pharm Sci 2018;10:29-34.

6. Thriveni VK, Manjunatha H, Ajesh K. Anti-inflammatory activity of curcumin and capsaicin augmented in combination. Int J Pharm Pharm Sci 2017:9:145-9.

7. Silverstein RM, Webster FX. Spectrometric Identification of Organic Compounds. $6^{\text {th }}$ ed. Hoboken, New Jersey: Wiley; 2005. p. 79-109.

8. Yadav VR, Suresh S, Devi K, Yadav S. Effect of cyclodextrin complexation of curcumin on its solubility and antiangiogenic and anti-inflammatory activity in rat colitis model. AAPS PharmSciTech 2009;10:752-62

9. Kalyan H, Ravi K, Biresh KS, Chowdary YA, Devgan M, Maddi R. UVvisible spectrophotometric estimation of curcumin in nanoformulation. Int J Pharmacogn 2015;2:127-30.

10. Raymond R, Paul J. Handbook of Pharmaceutical Excipients. $5^{\text {th }}$ ed. Washington, DC: Pharmaceutical Press; 2006. p. 110-3, 298-300, 794-5.

11. Ramesh AR, Pathak AR, Sakarkar DM, Kunjwani HK, Suhas B, Patel J. Formulation and evaluation of thiocolchicoside topical gel by using different method. Int J Phytopharm 2016;6:27-30.

12. Kalita V, Pegu P, Chetia P. Phytochemical screening and evaluation of antioxidant, anti-microbial and anti-inflammatory activity of Curcuma caesia. Int J Pharm Sci Res 2019;10:846-55.

13. Niyaz B, Kalyani P, Divakar G. Formulation and evaluation of gel containing fluconazole-antifungal agent. Int $\mathrm{J}$ Drug Dev Res 2011;3:109-28

14. Mizushima Y, Kobayashi M. Interaction of anti-inflammatory drugs with serum proteins, especially with same biologically active proteins. J Pharm Pharmacol 1968;20:169-73.

15. Umme H, Shivakumar HG, Osmani RA, Srivastava A, Varma NS. Development of a curcumin bioadhesive monolithic tablet for treatment of vaginal candidiasis. Iran J Pharm Res 2016;15:23-34 